\title{
THE EFFECTS OF PUBLIC PARTICIPATION ON ENVIRONMENTAL IMPACT ASSESSMENT
}

by Amori Kock*

\section{Introduction}

Every physical development in South Africa requires that significant consideration of any environmental impact must be given long before the development can commence. ${ }^{1}$ Environmental management, and environmental impact assessment (EIA) as one of its tools, is the regulation of any effect that people's actions, products or services may have on the environment. Environmental legislation is encompassed within the National Environmental Management Act 107 of 1998 (NEMA). Environmental law, however, is not a solitary area of law but must be read, and applied, through supreme legislation such as the Constitution ${ }^{2}$ and general legislation like the Promotion of Administrative Justice Act 3 of 2000 or the Spatial Planning and Land Use Management Act 16 of 2013. South Africa, therefore, lacks a single, comprehensive legislative framework for the compliance of environmental management resulting in great uncertainty in spite of various legislative works pertaining to the same issue. Public participation is considered a valuable component of the EIA process and should be encouraged through comprehensive community consultation. However, there seems to be a difference in view between development corporations and interested and affected parties on the value and degree of such participation. ${ }^{3}$

In accordance with section 24 of the Constitution, everyone has the right to an environment which is not harmful to one's health and for it to be protected for present and future generations. Section 32 of NEMA, in line with section 38 of the Constitution, allows for persons to act on behalf of the environment without those representative's rights necessarily being affected. ${ }^{4}$ The natural question arising from this is who can be included in the term 'people'. The Constitution clearly calls for any person who has an interest in the situation, or

* BCom Law (University of Pretoria), Final year LLB Student, University of Pretoria.

$1 \quad$ M Kidd Environmental Law (2011) 1.

2 The Constitution of the Republic of South Africa, 1996 (the Constitution).

3 C O'Faircheallaigh 'Public participation and environmental impact assessment: Purposes, implications, and lessons for public policy making' (2010) 30.1 Environmental Impact Assessment Review 19.

4 W du Plessis \& AA du Plessis 'Striking the sustainability balance in South Africa' in $M$ Faure \& W du Plessis (eds) The balancing of interests in environmental law in Africa (2011) 413. 
anyone bringing the application on behalf of someone who cannot bring such an application, before a competent court or tribunal. ${ }^{5}$ Furthermore, section 34 gives everyone the right of access to the courts in a fair and open trial. However, at present no specialised environmental courts are available to hear such an application pertaining to an environmental matter

Public participation is not only encouraged but also expected in every EIA in terms of NEMA and the Environmental Impact Assessment Regulations. Section 4 of the PAJA, ${ }^{6}$ specifically requires that if any administrative action could affect the legitimate expectations of any person (whether it be materially and/or adversely), such action must be constituted as procedurally fair. Therefore, every person that may possibly be affected by the construction of an environmentally detrimental project, must be notified and be given the opportunity to state their own case. ${ }^{7}$

With this research, I aim to address the practical aspect of legal compliance most major industry companies struggle to obtain. In South Africa, there seems to be an issue relating to legal compliance of environmental authorisations given by the Department of Environmental Affairs and Tourism (DEAT). Companies, specifically those companies which have a significant impact on the nonrenewable resources, are burdened with legal requirements that cannot be met, whether it be unreasonable or practically impossible to obtain. With every project undertaken by these companies an Environmental Management Plan (EMP) must be issued (by the company itself) outlining the expectations and limitations of the proposed project through an Environmental Impact Assessment (EIA) that clearly summarises the intended development and its impact ${ }^{8}$ Should the EMP be accepted by the Regional Manager, a Scoping Report will be provided, by the applicant, clearly outlining the legal requirements and limitations placed on the proposed project. These conditions are mostly vague, as to what is expected or uncertain of how it should be achieved

Companies and individuals, therefore, cannot approach a court (or tribunal) on issues relating to the interpretation of vague requirements as set out in an EMP. The Macsand case clearly highlighted the fact that the interpreter of legislation must consider

5 Sec 38 of the Constitution.

6 The Promotion of Administrative Justice Act 3 of 2000 (PAJA).

7 Sec 4 of PAJA (n 7 above).

8 T Humby 'The Environmental Management Programme: Legislative design, administrative practice and environmental activism' (2013) 130 South African Law Journal 6061. 
legislation as a whole. ${ }^{9}$ Furthermore, the legislation only invites the general public to raise concerns for upcoming events which can possibly jeopardise the environment. However, very few guidelines exist on how to achieve community involvement as factors such as uneducated people or mala fide intentions can adversely affect those companies aiming for a better developed community.

Ultimately this research aims to provide a link or alternative method to bridge the gap between the conflict of interest that arise between the industry's sometimes capital-driven goals and the public's more future orientated disposition.

\section{Contextualisation}

\subsection{Introduction}

Environmental law is based on two very distinct principles: the 'polluter pays'-principle and the precautionary principle. ${ }^{11}$ Both these principles relate to the manner in which environmental management and permitting are undertaken and implemented and should, therefore, be used as the building blocks to discuss any legal environmental issue.

The polluter pays principle was first coined in 1974 and means that the person who is responsible for the polluting, should also be responsible for the cost and prevention of said pollution. ${ }^{12}$ It is an economic principle as it imposes a cost on pollution for the polluter rather than being passed on to the consumer and reflecting in the price of the product. ${ }^{13}$ This principle gave way to a dual aspect view - a preventative and compensatory approach to environmental law. Regrettably, the South African legislation does not comprehensively cover this dual-approach, regardless of its recognition in the international sphere. At the other end of the spectrum, we find the precautionary principle entailing preventative measures against any action that may cause harm to the environment. ${ }^{14}$ The latter encompasses the idea that it will be better to avoid harm than try and remedy it later, resulting in a single approach view. The South African

9 C Botha \& B Bekink 'Macsand v City of Cape Town, Minister for Water Affairs and Environment, MEC for Local Government, Environmental Affairs and Development Planning, Western Cape Province, Minister for Rural Development and Land Reform and Minister for Mineral Resources 20124181 (CC)' 2015 De Jure 456.

10 A du Plessis 'Public participation, good environmental governance and fulfilment of environmental rights' (2008) 2 Potchefstroomse Elektroniese Regsblad 17.

11 Kidd (n 1 above) 7.

12 Kidd (n 1 above) 8.

13 ML Larsson 'The law of environmental damage: Liability and reparation' (1999) 90.

14 Kidd (n 1 above) 9. 
legislature prefers the precautionary principle as evident in section 2(4)(a)(vii) of NEMA. It is, therefore, safe to argue that South African environmental impact legislation is primarily based on the precautionary principle.

Other environmental principles include the responsibility to remediate any past harm to the environment or mitigate any unavoidable harm or viewing the environment from a public trust doctrine. Even though these views have substance, little to no weight has been attached to them in South Africa. ${ }^{15}$ However, in practice it is difficult to denote a singular approach to reduce or halt harmful operations, resulting in the selection and combination of various methods to reduce environmental damage. ${ }^{16}$

\subsection{History of environmental permitting and authorisations in South Africa}

The first EIA, as we know it today, was recognised by the USA in 1970 in its National Environmental Policy Act as a procedure to identify and investigate environmental consequences resulting from development. ${ }^{17}$ South Africa, as previously stated, only implemented similar provisions much later on, after realising its success and necessity in the international sphere. Broadly put there were 3 legislative mechanisms used to enact environmental legislation: the Constitution, NEMA and lastly issue specific legislation such as EIA Regulations. 18

During the environmental law revolution of the 1970's the EIA was debated as a necessary and appropriate tool to achieve environmental conservation. In 1972 the Committee on Environmental Conservation was appointed to advise the cabinet on environmental conservation matters and their corresponding impacts, but these procedures were never implemented. ${ }^{19}$ During this stage, public participation was strictly limited to the distribution of information to a limited number of interest groups and conservation lobby organisations. ${ }^{20}$ South Africa first considered the EIA process in 1977. Practical guidelines that would assist professional planners in effectively taking environmental consequences into consideration were published in

15 Kidd (n 1 above) 11.

16 Larsson (n 14 above) 89.

17 M Sowman, RF Fuggle \& $G$ Preston 'A review of the evolution of environmental evaluation procedures in South Africa' (1995) 15.1 Environmental Impact Assessment Review 46.

18 RF Fuggle \& MA Rabie 'Environmental Management: An Introduction' in HA Strydom \& ND Kings (eds) Environmental Management in South Africa (2011) 193.

19 Sowman et al (n 17 above) 49.

$20 \mathrm{~N}$ Rossouw \& K Wiseman 'Learning from the implementation of environmental public policy instruments after the first ten years of democracy in South Africa' (2004) 22.2 Impact Assessment and Project Appraisal 133. 
1980 but lacked in many areas and were never adopted. A Commission of Inquiry was appointed by the President in 1981 to consider the need for environmental legislation - the Commission's report proposed a bill to promote environmental conservation essentially providing the basis for the Environment Conservation Act 79 of 1989 (hereafter ECA). ${ }^{21}$

With the process of democratisation looming, environmental policy procedure had to also undergo serious changes. ${ }^{22}$ Although the ECA was South Africa's first piece of environmental legislation to coordinate and regulate matters that may be harmful to the environment, it did not contain any EIA elements or procedures. ${ }^{23}$ The international community started to exercise influence over South Africa to introduce EIA as a regulating mechanism for projects likely to have a substantial influence on the environment. In accordance with the ECA, a committee was established in the Council for the Environment namely the Committee for EIA. This committee was tasked to initiate research, workshops and gather all the necessary documentation on different EIA models available to South Africa. ${ }^{24}$ The Committee showed unanimous support for an ElA process in South Africa and developed and published an environmental management process they had coined Integrated Environmental Management (IEM) in 1989. The committee reasoned that the term EIA was too constrictive and narrow to encompass all the elements of the planning and reactive stages and that the process had to be flexible, generally applicable, widely accepted and practical. ${ }^{25}$ The IEM process applied to both the private and public-sector projects and developments and subject to approval by governmental authority. Chapter 5 of NEMA elaborates on the IEM process with section 23(2) providing the purpose of IEM. ${ }^{26}$ The difference between the terms IEM and EIA lies in the fact that IEM can be considered as a complete philosophy of the balance between the environment and development whereas EIA is merely a tool to accomplish the IEM philosophy. ${ }^{27}$ For purposes of this research, we will discuss the EIA specifically as a way to obtain IEM.

EIA, as we implement it today, was first published in terms of the 1989 ECA but has since gone through three very extensive revisions in 2006, 2010 and very recently in 2017 under NEMA. NEMA grew out of an environmental policy development process known as the Consultative National Environmental Policy Process that actively incorporates public participation and commenced on 29 January

Sowman et al (n 18 above) 49.

Rossouw et al (n 21 above) 133

Sowman et al (n 18 above) 49.

Sowman et al (n 18 above) 50

Sowman et al (n 18 above) 51

Fuggle \& Rabie (n 19 above) 204.

Enviropaedia 'Integrated Environmental Management' http://www.enviropaedia. com/topic/default.php?topic_id=141 (accessed 27 March 2013). 
1999. ${ }^{28}$ NEMA has been amended seven times since its commencement, two of which specifically concern the EIA framework. Both of these amendments were undertaken to broaden EIA principles and simplify the EIA process.

\subsection{Specific matters relating to the EIA process}

According to section 23(1) of NEMA, IEM systems identify and evaluate the actual and potential impacts that activities pose on the environment to assess the risks, consequences, and alternatives. It aims to mitigate these negative impacts and maximise any potential benefits. ${ }^{29}$ As a way to obtain and sustain integrated environmental governance, NEMA has implemented a legislative framework for the EIA process in section 24. This provision was later amended to extend certain matters in the 2006 EIA Regulations publication. ${ }^{30}$

The process of IEM, and more specifically EIA, can be broadly described in three stages. The first stage refers to the development and initial assessment of the proposed development. ${ }^{31}$ It is during this stage that all interested or affected parties (whether it be public or private) must be notified of the proposal together with the consideration of any and all mitigation measures. The proposal must set out the possibility of any significant impact that the project may pose to the environment. Should the authorities feel that the proposal is too vague and/or uncertain, it can be sent back to the developers for further investigation. ${ }^{32}$ The developer should also include a scoping report which will indicate the procedures and requirements for the impact assessment as well as other reasonable alternatives. The second stage deals with the authorities' decision to approve the proposal should it comply with the planning requirements. This stage created a special role for local government within environmental management requiring environmental sustainability issues to be integrated into municipal planning. ${ }^{33}$ Should the authorities, consisting of the municipal planners of the DEAT, approve the proposal, an environmental checklist must be compiled that indicates any conditions or constraints on the proposed development. The checklist will comprise of the identified environmental factors that may possibly be affected. ${ }^{34}$ The third and final stage of the IEM process concerns the implementation of the proposed development subject to the conditions of the environmental contract. Periodic

Kidd (n 1 above) 36.

Fuggle \& Rabie (n 19 above) 204.

As above.

Sowman et al (n 18 above) 55.

Sowman et al (n 18 above) 56 \& 59.

Rossouw et al (n 21 above) 137.

Sowman et al (n 18 above) 61. 
audits of the effects must be undertaken by the authorities to determine the compliance with the conditions of approval. ${ }^{35}$

The EIA process in South Africa is based on the sustainable development principle. This principle was confirmed in the $B P$ Southern Africa (Pty) Ltd $\vee$ MEC for Agriculture, Conservation and Land Affairs case, where J Claasen stated that sustainable development is the fundamental building block of environmental legal norms and that it should be regarded with the same seriousness as any pure economic principle. ${ }^{36}$ The principle is also encompassed in section 2(b)(iii) of our Constitution, making it a fundamental human right under Chapter 2 of the Bill of Rights. When any statutory provision is under scrutiny, by any organ of state which may exercise said function, the sustainability principle will be crucial with regard to economic and social development. ${ }^{37}$

\subsection{Conclusion}

Even though the EIA process, under the umbrella term IEM, has changed over the years, the fundamental principle of sustainable development that requires accountability, forms the basis of environmental legal compliance bringing us back to base with the "polluter-pays" and precautionary principles.

From the brief discussion on NEMA, and its provisions relating specifically to EIA, it is clear that NEMA is addressing the weaknesses of the past. It establishes a strategic approach to environmental governance and co-ordinates the functions of government and other key players. Furthermore, NEMA is systematically moving away from the classic command and control system on an ad-hoc basis. ${ }^{38}$ Although there are a lot more mechanisms to control enforcement and compliance than before, the South African legislative framework is still lacking in certain areas with the most prominent one being the effective application thereof. ${ }^{39}$ The current EIA practice in South Africa does not need any exhaustive legislative adjustments but must rather be better aligned under NEMA through a three level approach. The first approach is the improvement of current control mechanisms, the second approach calls for minor adjustments and the third for a complete replacement. ${ }^{40}$ This would result in only certain provisions being completely repealed with the focus on mildly adjusting the majority of provisions for a better holistic approach. The need for any

Sowman et al (n 18 above) 62.

(2004) ZAGPHC (18) 144.

Kidd ( 1 above) $36 \& 39$.

Fuggle \& Rabie (n 19 above) 221.

A Morrison-Saunders \& $F$ Retief 'Walking the sustainability assessment talk Progressing the practice of environmental impact assessment (EIA)' (2012) 36 Environmental Impact Assessment Review 12.

40 Morrison-Saunders et al (n 40 above) 12. 
further alignment must be viewed with a democratic approach - for the people and by the people. This is incorporated in the idea of public participation.

Public participation is a big role player in the EIA process. O'Faircheallaigh defines public participation as any form of interaction between a branch of government, corporate actors and the public. ${ }^{41}$ It is therefore an empowering mechanism for individual communities to allow communal aspirations or priorities to be taken into account in major decisions. ${ }^{42}$ Public participation in EIA assists in redistributing power from sole-government control to the general public. Participation in environmental decision making proves to be an effective tool to environmental legal compliance and effective solutions to environmental challenges. ${ }^{43}$ Public participation will be the deciding and key factors when the legislature considers any further amendments or addendums to our current EIA process and environmental legislative framework and therefore must be discussed in greater detail.

\section{Public participation}

\subsection{Introduction}

Any administrative action that is undertaken, must be lawful, reasonable and procedurally fair in terms of section 33 of the Constitution. Furthermore, should anyone's rights be adversely affected by said administrative action, those affected must receive written reasons for proposed action. ${ }^{44}$ This right has been enacted and broadened, by the legislature, with PAJA to provide for the review of administrative action by a court or independent and impartial forum. ${ }^{45}$ This entire process, wherein the potentially affected can convene with the prospective project team, takes shape in the form of public participation. The weight of public participation has been extended to be included within the scope of NEMA as it can be used as a tool to prevent environmental injustice. ${ }^{46}$ Since the effectiveness of environmental law depends, mostly, on administrative action which is lawful, reasonable and procedurally fair, it is of cardinal importance to examine and fully comprehend this right.

During the apartheid years in South Africa, policy formulation, together with any administrative action, was highly centralised,

41 O'Faircheallaigh (n 3 above) 20.

42 O'Faircheallaigh (n 3 above) 20.

43 Du Plessis (n 11 above) 10.

44 Kidd ( 1 above) 27.

45 Kidd (n 1 above) 27.

46 Secs 2(4)(b) - (o) of PAJA (n 7 above). 
secretive and dominated by the state and legislature. The entire apartheid era was designed to exclude the majority of people from public participation and therefore also keeping them from participating in decisions ultimately affecting their lives. ${ }^{47}$ It was this dark phase in our history that necessitated the need for the development of administrative, legal and social structures, including improved access to state-controlled information and the provision of reasons for any decision taken. Under our new democratic regime, it is deemed unethical and undemocratic to not involve the public and those who may experience the relevant environmental and social impacts. ${ }^{48}$ This fundamental shift, with particular reference to public participation in the EIA process, hopes to achieve a more equitable distribution of political power and by doing so, improving the quality of the decision-making process. ${ }^{49}$

According to Wilkinson, there are three general functional categories of public participation: education or informative, review or reaction and interactive or dialogue. ${ }^{50}$ Each one the abovementioned functions can be viewed as an integral part of the decision-making process and therefore cannot be applied in a singular manner. ${ }^{51}$ All three of the functions must be applied flexibly in terms of the degree of participation involved and in terms of the situation at hand. ${ }^{52}$ However, even though South Africa has an extensive environmental legislative framework in place for public participation, there has been little to no provision made for the socio-economic challenges we face on an everyday basis. ${ }^{53}$ The environmental law incorporates certain general and specific principles of administrative law as environmental issues are addressed in the principles of administrative law. Administrative law should therefore also be discussed in the light of the socio-economic challenges we face with regards to environmental and social responsibility.

\subsection{Administrative action}

Section 33 of the Constitution, together with Chapter 10 of the Bill of Rights, provides the basis for the protection and promotion of administrative action, including the field of environmental law. This section calls for administrative action which is lawful, reasonable and procedurally fair and for the provision of sound reasons for any administrative action taken. The realisation of the right to just

51 P Wilkinson 'Public participation in environmental management: A case study' Natural Resources Journal 16 (1976) 117.

52 Wilkinson (n 52 above) 119.

53 A du Plessis (n 11 above) 20. 
administrative action is based on the contingency of two other rights: the right to information and the right to access of courts, tribunals or forum. ${ }^{54}$ Lastly, the Constitution also specifically realises the right to an environment which is not harmful to one's health or well-being while protecting the environment for the benefit of present and future generations. ${ }^{55}$ The bare fact that the legislature does not only encompass environmental rights multiple times in the Bill of Rights, the most protected piece of legislative work in South Africa, but also goes further to specifically include the application thereof under administrative action, emphasises the fact that environmental conservation and preservation is deemed to be a fundamentally important aspect in South Africa. Therefore, the application of section 24 is strengthened by section 33, guaranteeing that all environmental decisions must be undertaken in a lawful, reasonable and procedurally fair manner. However, these fundamental rights might be deemed worthless if there is no guarantee of formal participation by the right holders in the implementation. ${ }^{56}$

The ambit of administrative power is determined by either the empowering statute or provision. The PAJA is empowered under section 33 of the Constitution and applies to all actions of administrators and particularly that of an environmental administrator. The Act lays down certain general requirements as well as certain specific requirements such as procedural fairness and the providing of reasons for any decision that may adversely affect another's rights. ${ }^{57}$ In the environmental sphere, it can be concluded that any action by an environmental administrator to implement or execute policy, will be regarded as administrative action even if just a simple decision is taken. ${ }^{58}$ PAJA clearly outlined the requirements for lawful administrative action, procedural fairness, and reasonableness in section 6. All three of the abovementioned requirements are of vital importance, but for the purposes of this research, focus shall be directed upon procedural fairness to fully comprehend the notion of public participation.

PAJA distinguishes between administrative action that affects any one singular person (section 3 ) and administrative action that affects the public (section 4). In the rare instance that an environmental decision only adversely affects one individual, the injured party must be able to prove that his or her right or a legitimate expectation was materially and adversely affected. ${ }^{59}$ The second and generally more occurring scenario if that of administrative action that has a general 
impact on the public, this usually occurs with the enactment of proposed environmental legislation or action. ${ }^{60}$ Should a section 4 scenario be present, an administrator must hold a public inquiry following a notice-and-comment procedure or a combination of the above. ${ }^{61}$ This public inquiry encompasses the idea of public participation. Public participation is therefore, a crucial element in the fulfilment of environmental rights and essentially guaranteeing fundamental rights and good environmental governance.

\subsection{Public participation - the what, why and when}

Broadly put, public participation can be reduced to the communication of concerns on public issues by those concerned and/ or affected. However, if properly defined it can be viewed as the real involvement of all social actors in social and political decision-making processes that will potentially affect the communities in which they live and work. 62

Public participation is the involvement of individuals, who will be either positively or negatively affected by a proposed project, programme, plan or policy where they can significantly influence the decision-making process. ${ }^{63}$ Public participation has been used as a term for citizen power - a process that empowers the formerly marginalised groups by redistributing executive power. It is also a form of participatory democracy based on the constitutional values of equality, dignity, and freedom. Public participation can be found at different levels of society and in many forms. Public participation can be applied in a formal manner with public inquiries, commissions, and notices or can be effected in a more informal manner involving protest marches, media campaigns, and petitions. ${ }^{64}$ It is this process that ensures that big corporations have a vast collection of information at their disposal that they would not usually have encountered, as well as providing the decision makers with the information on actual costs and benefits the proposed project will yield. Public participation can assist with problem solving by suggesting ideas, concepts, solutions and resources and the calculation of the political consequences. ${ }^{65}$ However, developers do not usually favour public participation, regardless of the many advantages, as it may risk the completion of a high-profile project as

60 Kidd (n 1 above) 231.

61 Sec 4 of PAJA (n 7 above).

62 A du Plessis (n 11 above) 4.

63 A Glucker, PPJ Driessen, A Kolhoff \& Runhaar H.A.C et al 'Public participation in environmental impact assessment: why, who and how?' Environmental Impact Assessment Review 43 (2013) 105 (Glucker et al).

64 Glucker et al (n 64 above) 105.

65 O'Faircheallaigh (n 3 above) 21. 
well as being costly and time consuming. ${ }^{66}$ Public participation has been used as a systemic attempt to delay and block development and in extreme cases even completely stop the projects. ${ }^{67}$

Public participation has been linked to various statutory frameworks in South Africa including (but not restricted to) the PAJA, NEMA and the Promotion of Access to Information Act 2 of 2002 (PAIA). ${ }^{68}$ All of the abovementioned legislative frameworks aim to improve the quality and extent of the information that should be made available to those who want to exercise protection over their fundamental rights. ${ }^{69}$ However, there is still disagreement among scholars, legal practitioners of big corporations and the legislature on the extent of information supplied to 'the public' and the weight that these opinions must carry. The wider the spectrum of people and groups that are allowed to participate will not only bear a paramount risk to the developer but will eventually frustrate the participants resulting in a decrease in willingness to participate in the EIA process. $^{70}$

\subsection{Public participation in the EIA process}

Public participation, for the extent of this article, is a framework of regulatory requirements that a development company must comply with in order to obtain a permit for a proposed project in the energy, mining or natural resource sector. ${ }^{71}$ The requirements must be imposed by general legislation or more specific environmental protection legislation to allow the public to make written or oral submissions to the regulatory body. In South Africa, EIA is the framework for this process that must be taken into account when the regulatory body either makes the decision or a recommendation to the Minister of Environmental Affairs. ${ }^{72}$

Most scholars agree that public participation holds the key to effective environmental assessment, by improving the quality of the decisions taken, but disagree on the meaning and extent of the process. ${ }^{73}$ Furthermore, academics also seem to be divided on the objective that public participation pursues behind the backdrop of the EIA process.

67 Glasson et al (n 67 above) 154.

68 Act 2 of 2000.

69 Sec 32 of the Constitution (n 2 above).

70 Glucker et al (n 64 above) 109.

71 B Barton 'Underlying concepts and theoretical issues in public participation in resources development' (2002) Human rights in natural resource development: Public participation in the sustainable development of mining and energy resources 78 .

72 Barton (n 72 above) 78.

73 Glucker et al (n 64 above) 104. 
Public participation in the EIA framework and its importance have been formally recognised by both legislation and international law. During the 1992 Rio Conference on Environment and Development, the United Nations acknowledged that environmental issues are best handled when all concerned citizens, on every level, are actively involved in any process affecting the natural environment. The 1998 Convention on Access to Information, Public Participation in Decision Making and Access to Justice in Environmental Matters, was the first framework to set out the minimum requirement for public participation, resulting in the signatory states adopting measures to implement public participation. South Africa adopted NEMA together with the 2014 Environmental Impact Assessment Regulations framework to address the matter of the EIA and specifically its relationship with the public participation process in Chapter $6 .^{74}$

In terms of the EIA Regulations of 2017, the developer must submit the basic assessment report, including the preliminary EIA, to all the registered, interested and affected parties at least 30 days prior to the initiation of the proposed project. ${ }^{75}$ Furthermore, the developer must provide access to all information that reasonably or may possibly influence the decision to the competent authority and relevant, registered and affected parties. ${ }^{76}$ The statute clearly set out the process that must be followed, by the developer, in section 41 of the EIA Regulations including the placing of a public notice and giving written notice to the jurisdictional municipality and those who will, possibly, be affected the most. ${ }^{77}$ The legislature went further to include alternative methods of public participation to include the disadvantaged or illiterate.

It seems as if the legislature has, extensively, tried to accommodate everyone who might want to participate in this process either for protection of a personal right or as a locus standi party in terms of section 38 of the Constitution in pursuance of the objectives of public participation. The objects of public participation have derived from both normative and substantive ideas and principles, including the development of citizenship skills and social learning to the enhancement of the quality of decisions made. ${ }^{78}$ However, the real value of public participation should be explored: government uses public participation as a valuable role in filling information gaps to render information contestable while the industry suffers under the heavy legal constraints; the developer gains valuable information but

74 Amendment to the Environmental Impact Assessment Regulations 326 of 2017 published under Government Notice No. 982, Gazette No 3822 (EIA Regulations 2017).

75 Sec 40(1) of ElA Regulations 2017 (n 75 above).

76 Sec 40(2) of EIA Regulations 2017 (n 75 above).

77 Sec 41 of EIA Regulations 2017 (n 75 above).

78 Glucker et al (n 64 above) 107. 
the public is burdened by an intimidating and time consuming process. $^{79}$

Participation definitely yields an educative function by enabling citizens to develop a comprehensive understanding of the government system and providing insights into the interests of fellow citizens. ${ }^{80}$ This is a very important quality as it empowers community members to exercise control over their own environment and future development at every stage possible. However, in practice, the powerless are the least likely to participate in the EIA process due to its daunting and intimidating nature. ${ }^{81}$

\subsection{Conclusion}

From the above stated arguments, it is clear that South Africa already has a clear statutory framework in place to regulate EIA processes and procedures in various statutes and regulations. However, it seems that the current situation leans more towards the effective and real value that these processes could yield to both the regulator and the regulated. Most researchers agree that public participation enhances the decision-making process by identifying, anticipating, recognising and avoiding of potential impacts ${ }^{82}$ and risks that would otherwise not have been identified. ${ }^{83}$

Regard must also be given to the substantive value the public's involvement must carry; many scholars believe that the general public is not qualified enough to provide a meaningful contribution to the planning stage of a complex development. In the Netherlands, the developer must provide a non-technical summary to the public and other decisions makers during the public participation process. South Africa, however, still seems to be lacking this statutory provision in the various and comprehensive EIA Regulations. ${ }^{84}$ It seems as if public participation will remain a weak and, sometimes, neglected aspect of the EIA process until both the developer and the legislature see that the benefit of public participation can exceed the cost thereof. ${ }^{85}$ Public participation will only become an invaluable commodity to the community if it seeks to conform to the public's needs and realistic abilities. Even though legislation like the PAJA, PAIA and EIA Regulations aim to involve an affected community, the involvement will only yield the results and outcomes they are reasonably capable

79 O'Faircheallaigh (n 3 above) 25.

80 O'Faircheallaigh (n 3 above) 22.

81 O'Faircheallaigh (n 3 above) 23.

82 EIA Regulations 2017 (n 75 above).

83 DF Luca \& $\mathrm{K}$ Wallace-Jones 'The effectiveness of provisions and quality of practices concerning public participation in EIA in Italy' (2000) 20.4 Environmental Impact Assessment Review 5. 
of. This will remain a problem in South Africa until such a time that socio-economic problems are sufficiently addressed and the real consequences of public participation are effectively considered whether it be through the process of EIA or a more socially orientated approach.

\section{$4 \quad$ Recommendations}

\subsection{Introduction}

The EIA system has been implemented in South Africa during the last two decades and has gone through many phases and changes even though one communal goal has remained: sustainability. The EIA process is not a scientific method where scientific facts and knowledge must be applied to solve a problem, but it is a platform where people with different interests can come together and approach a situation in an evaluative manner. ${ }^{86}$ The EIA process is in its very nature dependent on political will and change and is therefore deeply dependent on the conscious involvement of effective public participation to achieve fair and sustainable development. ${ }^{87}$

Public participation is, however, to a large extent, considered to be an advantage rather than a deterrent. It is a mechanism to ensure that all relevant issues, those reasonably foreseeable by the developer and even those whose likeliness was not anticipated, are duly considered before the development may commence. ${ }^{88}$ It can also be viewed as a method to acquire more innovative, viable and publicly accepted ideas and solutions. Alternative methods and solutions that were identified are also easier to incorporate during this phase of development and usually at a fraction of the cost. ${ }^{89}$ It seems as though the effectiveness of EIA and public participation, as with beauty, lies within the eyes of the beholder.

\subsection{Effectiveness of current system}

The EIA process gives effect to rights contained in the Constitution, NEMA, PAJA, and PAIA. Each of these rights is accompanied by factors that can be considered positive or detrimental depending on the view taken. The EIA process and NEMA has an effect on all three spheres of

$86 \mathrm{~N}$ Craik 'The international law of environmental impact assessment: process, substance and integration' 196 Cambridge: Cambridge University Press (2008) 178.

87 C Vasconcelos, A Hamilton \& P Barrett 'Public participation in EIA: A study from a Portuguese perspective’ (2000) 2.04 Journal of Environmental Assessment Policy and Management 562.

88 Glasson et al (n 67 above) 155.

89 Glasson et al (n 67 above) 156. 
government: legislative, executive and judicial and should, therefore, be approached with care as any consequence may have a ripple effect on either the EIA process or environmental law as a whole. The major factors that influence the effectiveness of the EIA system include the public participation process and the identification of those who should be involved. ${ }^{90}$

There seems to be uncertainty among academics on who should be involved in the public participation process as there is no fixed definition and terms such as 'public', 'stakeholders' and 'citizens' are used interchangeably when this matter is addressed. ${ }^{91}$ The only consensus is that it definitely includes any person, group or organisation that will be affected by the development in an either beneficial or harmful manner. This consensus, though narrower than the general inclusion, only aims to exclude those who will not be able to constructively contribute to the process. ${ }^{92}$ This notion makes perfect sense as the involvement of such individuals will be inefficient and result in wasted time and money; however, in ElA practice, anyone who has interest in a given project is invited to participate. Even though this practice is democratic and reasonable in its nature, it will lead to many expectations not realised or met. ${ }^{93}$

Another constraint the legislature has on an effective public participation system is that of the amount and extent of information that has to be made available to the participants in the process. In terms of PAIA, the developer must disclose any and all information that may be an imminent and serious environmental risk to the participants as they have a constitutional right to the relevant information. ${ }^{94}$ This sometimes creates difficulties to both the developer and the public. The information supplied by the developer usually consists of technical concepts and complex data that requires more than even basic literacy skills that must be analysed and judged by a, sometimes even illiterate, laymen. ${ }^{95}$ The developer, through the supply of this information, also immediately incriminates itself as sensitive information, by way of the PAIA, can subject the company to an environmental audit. Companies do not enjoy the same constitutional protection of self-incrimination as natural persons do making them susceptible to a criminal conviction. ${ }^{96}$

It is therefore clear that the EIA process in South Africa is implemented with a rigid regulatory framework but the practice

92 As above.

93 As above.

94 Fuggle \& Rabie (n 19 above) 215.

95 Vasconcelos et al (n 88 above) 573.

96 Hayes \& Tshabalala, SA Media for the University of the Free State Business Day 'Conflict over environmental information' (13 October 2003) 6. 
thereof needs attention and thought. If South Africa can combine its quick processing time, to deliver an EIA authorisation, with efficient and effective public participation, it will improve community involvement and eventually stimulate economic development.

\subsection{Possibility of alternatives and environmental courts}

The possibility to move away from an EIA system does not constitute a practical solution in the slightest. Participation in EIA is considered vital in environmental management and is required for international recognition. South Africa must therefore not consider alternatives to the EIA system and its components, but rather consider ways to enhance the potential it may yield. As extensively discussed in part 4, the South African environmental system is in need of practical directives to complement the comprehensive legislative framework and make the entire process as efficient and comfortable as possible. Currently, the general courts are burdened with complex environmental prosecutions and intricate EIA interpretations for which they are neither trained nor experienced in, resulting in cases being decided on facts proved beyond any doubt rather than reasonable doubt. ${ }^{97}$

The South African judiciary has frequently been called upon to apply, interpret and pronounce the validity of environmental statutory provisions. These applications are heard by a local court as no explicit constitutional provision has been made for environmental courts. ${ }^{98}$ The past 20 years saw two specialised environmental courts, situated in Hermanus and Port Elizabeth respectively, being shut down due to an unwillingness from the Department of Justice and Constitutional Development despite its success. ${ }^{99}$ As of May 2017, no reconsideration has been done to reinvoke these specialised courts or a similar forum or tribunal as envisaged in the Constitution.

It is my respected view that for the EIA process to be as efficient as theoretically possible, the improvements have to start prior to the implementation of public participation. If greater emphasis is placed on the reasoning and method of the scoping process, both the developer and decision maker will be more open to an extensive public participation process. An enhanced public participatory process will yield a more valuable outcome for the developers and encourage members of the general public to become involved in their own communities. This pure and ideal, yet extremely limited recommendation, craves empirical research that cannot be obtained in a worthy manner at an undergraduate level. 


\subsection{Social impact assessment}

Public participation essentially provides a framework for community empowerment by addressing socio-economic problems through consideration of a Social Impact Assessment. ${ }^{100}$ However, South African communities do not harness a belief in public participation making it inherently more difficult to promote meaningful participation, especially in disadvantaged communities. Social impacts are not treated as a priority issue in the EIA process as socioeconomic factors are not taken into consideration when assessing public participation. Many community members targeted for public participation are not properly educated about their rights contained in either NEMA or the Constitution or struggle to grapple the basic concepts of the proposed activities. ${ }^{101}$

Social impacts are those impacts stemming from the everyday way in which people and communities work, live and interrelate to one another to meet the needs of a society. ${ }^{102}$ A Social Impact Assessment (SIA) refers to the process to assess the potential social consequences that are likely to follow from the proposed action whether it be intended, unintended, positive or negative. ${ }^{103} \mathrm{SIA}$ can be used to assess the costs and benefits of the activity and how and when they will likely be distributed among the different stakeholders over the course of the development. SIA, therefore, is a complementary process as it incorporates all key shareholders and not just those who will be involved in the public participation process making it a more democratic and transparent system. ${ }^{104}$ In South Africa, as with other developing countries, the SIA process is considered to be incorporated within the EIA regulatory framework and aim to alleviate socioeconomic problems, yet is also lost in the balance in obtaining the global goal of EIA. ${ }^{105}$

A possibility to consider can be the complementary process of SIA to assess the costs and benefits of the activity and how and when they will likely be distributed among the different stakeholders over the course of the development. In South Africa, as with other developing countries, the SIA process is considered to be incorporated within the EIA regulatory framework and aim to alleviate socio-economic problems yet is also lost in the balance in obtaining the global goal of

100 JA Du Pisani \& LA Sandham. 'Assessing the performance of SIA in the EIA context: A case study of South Africa' (2006) 26.8 Environmental Impact Assessment Review 718.

101 As above.

102 As above.

103 As above.

104 Du Pisani et al (n 101 above) 708.

105 Du Pisani et al (n 101 above) 711. 
EIA and therefore not recognised or valued for the collective value it can represent. ${ }^{106}$

\subsection{Conclusion}

EIA has been part of the South African legislative framework since 1997 and has been extensively revised on at least 3 occasions (2006, 2010 and very recently in 2017) in its pursuance of sustainability. However, the mere inclusion of the sustainability principles in our legislation has not yet ensured success in practice leaving an undesirable gap implementation gap. ${ }^{107}$ South Africa does not require any additional or extensive legislative amendments to ensure greater compliance with NEMA or EIA Regulations but rather a more practical and hands-on approach by the EIA practitioners already on hand. If our EIA practitioners were to change their regular EIA process by actively searching and acquiring sustainability, the passion will spread to other peers, colleagues, and communities ${ }^{108}$. The real value of EIA and public participation needs to be re-established among the developers and the executive body to actively better the process.

Due consideration must also be given to the social impacts that the EIA process yields by empowering disadvantaged communities and strengthening democratic processes. Furthermore, South Africa needs to find a proper balance between the participatory processes and decision-making responsibility if we are to obtain social justice, democracy, and sustainable development. ${ }^{109}$ If public participation were to be conducted in a very prudent an conscientious manner it will add value to the EIA process by enhancing environmental awareness and strengthening active citizenship resulting in a society that is concerned with the sustainability of their environment and that of the future generations. ${ }^{110}$

\section{$5 \quad$ Final thoughts and conclusion}

Even though the EIA process has changed over the years, the fundamental principle of sustainable development that requires accountability forms the basis of environmental legal compliance.

The current EIA practice in South Africa does not need any exhaustive legislative adjustments but must rather be better aligned under NEMA with a democratic approach - for the people and by the

106 Du Pisani et al (n 101 above) 708 \& 711.

107 A Morrison-Saunders \& F Retief 'Walking the sustainability assessment talk Progressing the practice of environmental impact assessment (EIA)' (2012) 36 Environmental Impact Assessment Review 12 (Morrison-Saunders et al.).

108 Morrison-Saunders et al (n 108 above) 13.

109 Du Pisani et al (n 101 above) 720.

110 Vasconcelos et al (n 88 above) 578. 
people. ${ }^{111}$ South Africa seems to lack appreciation for the need of various and comprehensive EIA Regulations to address socio-economic problems. It seems as if public participation will remain a weak and, sometimes, neglected aspect of the EIA process until it is clear to everyone involved that the benefit of public participation can exceed the cost thereof. Public participation will only become an invaluable commodity to the community if it seeks to conform to the public's needs and realistic abilities.

One of the major areas of law that will require further research and planning is public participation. Public participation in EIA assists in redistributing power from sole-government control to the general public. Participation in environmental decision making is an effective tool to environmental legal compliance and effective solutions to environmental challenges by identifying key stakeholders and even negotiation parties. It enhances the decision-making process by identifying, anticipating, recognising and avoiding of potential impacts and risks that would otherwise not have been identified solely by the developer. ${ }^{113}$ Moreover, it has proved to assist developers to think and react in new ways by offering innovative suggestions and concepts that are usually forthcoming from a new and fresh perspective. 